\title{
DECLARAÇÃO DA CONFERÊNCIA REGIONAL DE EDUCAÇÃO SUPERIOR NA AMÉRICA LATINA E NO CARIBE
}

Educação Superior é um bem público social, um direito humano e universal
e um dever do Estado. Esta é a convicção e a base para o papel estratégico
que deve assumir nos processos de desenvolvimento sustentável dos países da região.

Na Conferência Regional de Educação Superior na América Latina e no Caribe (CRES), realizada de 4 a 6 de junho de 2008, na cidade de Cartagena de Índias, Colômbia, com o apoio do Instituto Internacional da UNESCO para a Educação Superior na América Latina e no Caribe (IESALC-UNESCO) e o Ministério de Educação Nacional da Colômbia, com a colaboração dos governos do Brasil, Espanha, México e da República Bolivariana da Venezuela, participaram presencialmente mais de 3.500 integrantes da comunidade acadêmica regional - diretivos, professores, pesquisadores, estudantes, funcionários administrativos, representantes de governos e de organismos nacionais, regionais e internacionais, de associações e redes e outros interessados na Educação Superior. A CRES 2008 foi transmitida pela Internet em quatro idiomas a todos os países da América Latina e do Caribe (ALC) e para o mundo a partir dos sites da CRES, da UNESCO-Paris, do Ministério de Educação Nacional da Colômbia e do Ministério da Educação do Brasil, e também por rádio e televisão. Esta Conferência contribuiu para identificar as principais demandas da América Latina e do Caribe com a perspectiva da Conferência Mundial de Educação Superior, prevista para o ano 2009, assim como as idéias que fundamentam e impulsionam a consolidação, expansão e crescente qualidade e pertinência da Educação Superior na região.

A CRES 2008 realizou-se a 10 anos da Conferência Mundial de Educação Superior (1998), a 12 anos da Conferência Regional de Havana (1996) e a 90 anos da Reforma de Córdoba, cujos princípios constituem hoje orientações fundamentais em matéria de autonomia universitária, co-governo, acesso universal e compromisso com a sociedade.

O amplo processo de preparação deste evento contou com a ativa participação das comunidades acadêmicas da região, incluídos os estudantes, representados pela Organização Continental Latino-Americana e Caribenha de Estudantes (OCLAE). Tal participação foi realizada em múltiplos fóruns e encontros de caráter nacional, sub-regional e regional, cujas conclusões nutriram o evento. Por outro lado, os estudos coordenados pelo IESALC conduziram à elaboração dos documentos amplamente divulgados que serviram de base para o debate nesta Conferência. 
O balanço realizado permite visualizar, em termos prospectivos, as demandas e as oportunidades que se colocam na Educação Superior da região à luz da integração regional e das mudanças no contexto global, com o objetivo de configurar um cenário que permita articular, de forma criativa e sustentável, políticas que reforcem o compromisso social da Educação Superior, sua qualidade e pertinência e a autonomia das instituições. Essas políticas devem visar a uma Educação Superior para todos e todas, tendo como meta alcançar uma maior cobertura social com qualidade, eqüidade e compromisso com nossos povos; devem induzir o desenvolvimento de alternativas e inovações nas propostas educativas, na produção e transferência de conhecimentos e aprendizagens, assim como promover o estabelecimento e consolidação de alianças estratégicas entre governos, setor produtivo, organizações da sociedade civil e instituições de Educação Superior, Ciência e Tecnologia. Devem também considerar a riqueza da história, das culturas, das literaturas e das artes do Caribe e favorecer a mobilização das competências e dos valores universitários desta parte de nossa região, para edificar uma sociedade latino-americana e caribenha diversa, forte, solidária e perfeitamente integrada.

A Conferência Regional de Educação Superior 2008 faz um urgente e enfático chamado aos membros das comunidades educativas, particularmente aos responsáveis pela tomada de decisões políticas e estratégicas, aos responsáveis dos Ministérios de Educação Superior, de Cultura e de Ciência e Tecnologia, às organizações internacionais, à própria UNESCO e aos atores e pessoas envolvidos nas tarefas educativas e universitárias, para que considerem as demandas e as linhas de ação emanadas do debate ocorrido neste fórum, sobre as prioridades que a Educação Superior deve assumir e partindo de uma clara consciência a respeito das possibilidades e contribuições que ela apresenta para o desenvolvimento da região.

Os desafios e obstáculos que devemos enfrentar são de tal magnitude que, no caso de não serem atendidos com oportunidade e eficácia, se aprofundarão as diferenças, desigualdades e contradições que hoje impedem o crescimento da América Latina e do Caribe com eqüidade, justiça, sustentabilidade e democracia para a maioria dos países que a integram. Esta Conferência Regional assinala que, apesar dos avanços na direção de uma sociedade que busca mudanças e referentes democráticos e sustentáveis, ainda faltam grandes transformações nos eixos que dinamizarão o desenvolvimento da região, entre os quais, um dos mais importantes, é a Educação e, em particular, a Educação Superior.

Por isso, convictos do valor primordial da Educação Superior na criação de um futuro melhor para nossos povos, declaramos:

\section{A - Contexto}

1 - A construção de uma sociedade mais próspera, justa e solidária e com um modelo de desenvolvimento humano integral sustentável, deve ser assumida por todas as nações do Mundo e pela sociedade global em seu conjunto. 
Nesse sentido, as ações para o cumprimento dos Objetivos do Milênio devem constituir-se numa prioridade fundamental.

2 - Nossa região é marcadamente pluricultural e multilingüe. A integração regional e a abordagem dos desafios que enfrentam nossos povos requerem enfoques próprios que valorizem nossa diversidade humana e natural como nossa principal riqueza.

3 - Em um mundo onde o conhecimento, a ciência e a tecnologia desempenham um papel de primeira grandeza, o desenvolvimento e o fortalecimento da Educação Superior constituem um elemento imprescindível para o avanço social, a geração de riqueza, o fortalecimento das identidades culturais, a coesão social, a luta contra a pobreza e a fome, a prevenção da mudança climática e a crise energética, assim como para a promoção de uma cultura de paz.

\section{B - A Educação Superior como direito humano e bem público social}

1 - A Educação Superior é um direito humano e um bem público social. Os Estados têm o dever fundamental de garantir este direito. Os Estados, as sociedades nacionais e as comunidades acadêmicas devem ser os atores que definem os princípios básicos nos quais se fundamenta a formação dos cidadãos e cidadãs, cuidando para que ela seja pertinente e de qualidade.

2 - O caráter de bem público social da Educação Superior se reafirma à medida que o acesso à mesma seja um direito real de todos os cidadãos e cidadãs. As políticas educacionais nacionais constituem a condição necessária para favorecer o acesso a uma Educação Superior de qualidade, mediante estratégias e ações conseqüentes.

3 - Considerando a imensa tarefa de expandir a cobertura que se apresenta para os países da América Latina e do Caribe, tanto o setor público quanto o privado estão obrigados a outorgar uma Educação Superior com qualidade e pertinência, razão pela qual os governos devem fortalecer os mecanismos de reconhecimento que garantam a transparência e a condição de serviço público.

4 - Na América Latina e no Caribe, particularmente, faz-se necessária uma Educação que contribua eficazmente para a convivência democrática, tolerância e promoção de um espírito de solidariedade e de cooperação; que construa a identidade continental; que gere oportunidades para quem hoje não as tem e que contribua, com a criação do conhecimento, para a transformação social e produtiva de nossas sociedades. Em um continente com países que emergem da terrível crise democrática que provocaram as ditaduras, e que ostenta a penosa circunstância de ter as maiores desigualdades sociais do Planeta, os recursos humanos e o conhecimento serão as principais riquezas de todas quantas dispusermos. 
5 - As respostas da Educação Superior às demandas da sociedade terão que se embasar na capacidade reflexiva, rigorosa e crítica da comunidade universitária ao definir suas finalidades e assumir seus compromissos. É iniludível a liberdade acadêmica para poder determinar suas prioridades e tomar suas decisões segundo os valores públicos que fundamentam a ciência e o bem-estar social. A autonomia é um direito e uma condição necessária para o trabalho acadêmico com liberdade e, por sua vez, uma enorme responsabilidade para cumprir sua missão com qualidade, pertinência, eficiência e transparência em face às demandas e desafios da sociedade. Compreende também a prestação social de contas. A autonomia implica um compromisso social e ambos devem necessariamente caminhar juntos. A participação das comunidades acadêmicas na gestão e, em especial, a participação dos estudantes tornamse indispensáveis.

6 - A Educação Superior como bem público social enfrenta correntes que promovem sua mercantilização e privatização, assim como a redução do apoio e financiamento do Estado. É fundamental reverter esta tendência, de tal forma que os governos da América Latina e do Caribe garantam o financiamento adequado das instituições de Educação Superior pública e que estas respondam com uma gestão transparente. A Educação não pode, de modo algum, reger-se por regulamentos e instituições com fins comerciais, nem pela lógica do mercado. O deslocamento do nacional e do regional em direção ao global (bem público global) tem como conseqüência o fortalecimento de hegemonias que existem de fato.

7 - A Educação oferecida por provedores transnacionais, isentos de controle e orientação por parte dos Estados nacionais, favorece uma Educação descontextualizada, na qual os princípios de pertinência e eqüidade ficam deslocados. Isso amplia a exclusão social, fomenta a desigualdade e consolida o subdesenvolvimento. Devemos promover em nossos países as leis e os mecanismos necessários para regular a oferta acadêmica, especialmente a transnacional, sob todos os aspectos-chaves de uma Educação Superior de qualidade.

8 - A incorporação da Educação como um serviço comercial no marco da Organização Mundial de Comércio (OMC) foi sumariamente rejeitada por diversas organizações relacionadas diretamente com a Educação Superior. Essa incorporação constitui uma forte ameaça para a construção de uma Educação Superior pertinente nos países que aceitem os compromissos exigidos no Acordo Geral de Comércio e Serviços, e isto supõe graves danos para os propósitos humanistas de uma Educação integral e para a soberania nacional. Assim sendo, nós, da CRES, advertimos os Estados da América Latina e do Caribe sobre os perigos que implica aceitar os acordos da OMC e, em seguida, se verem obrigados por eles, entre outros aspectos lesivos, a destinar fundos públicos para empreendimentos privados estrangeiros implantados em seu 
território, em cumprimento do princípio do "tratamento nacional" que nele se estabelece. Afirmamos, ainda, nosso propósito de agir para que a Educação, em geral, e a Educação Superior, em particular, não sejam consideradas como serviço comercial.

\section{C - Cobertura e modelos educativos e institucionais}

1 - Para assegurar um significativo crescimento da cobertura educacional requerida para as próximas décadas, torna-se imprescindível que a Educação Superior gere as estruturas institucionais e as propostas acadêmicas que garantam o direito à mesma e a formação do maior número possível de pessoas competentes, destinadas a melhorar substancialmente o suporte sócio-cultural, técnico, científico e artístico que venham a requerer os países da região.

2 - Em vista da complexidade das demandas da sociedade para a Educação Superior, as instituições devem crescer com o horizonte da diversidade, flexibilidade e articulação. Isso é particularmente importante para garantir o acesso e a permanência em condições eqüitativas e com qualidade para todos e todas, e imprescindível, portanto, para integrar à Educação Superior setores sociais como os trabalhadores, os pobres, aqueles quem vivem em lugares afastados dos principais centros urbanos, as populações indígenas e afro-descendentes, pessoas portadoras de necessidades especiais, migrantes, refugiados, pessoas em regime de privação de liberdade e outras populações carentes ou vulneráveis.

3 - A diversidade cultural e a interculturalidade devem ser promovidas em condições eqüitativas e mutuamente respeitosas. $\mathrm{O}$ desafio não se refere apenas a incluir indígenas, afro-descendentes e outras pessoas culturalmente diferenciadas nas instituições, tal como existem na atualidade. Antes de tudo, urge transformar as instituições para que sejam mais pertinentes com a diversidade cultural. É necessário incorporar o diálogo de saberes e o reconhecimento da diversidade de valores e modos de aprendizagem como elementos centrais das políticas, planos e programas do setor.

4 - Satisfazer o aumento das exigências sociais pela Educação Superior requer aprofundar as políticas de eqüidade para o ingresso e instrumentar novos mecanismos de apoio público aos estudantes (bolsas, residências estudantis, serviços de saúde e alimentação, tanto como o acompanhamento acadêmico), destinados a permitir sua permanência e bom desempenho nos sistemas.

5 - Produzir transformações nos modelos educativos para vencer os baixos níveis de desempenho, o atraso e o fracasso estudantil, pressupõe formar um maior número de professores que sejam capazes de utilizar o conjunto de modalidades didáticas presenciais ou virtuais, adequadas às necessidades heterogêneas dos estudantes e que, além do mais, saibam desempenhar-se eficazmente em espaços educativos onde atuam pessoas de distintas procedências sociais e contextos culturais. 
6 - Avançar em direção à meta de prover a Educação Superior de forma generalizada ao longo de toda a vida requer reivindicar e dotar de novos conteúdos os princípios de ensino ativo, segundo os quais os principais protagonistas são, individual e coletivamente, os que aprendem. Somente haverá ensino ativo, permanente e de alto nível se este estiver vinculado, de maneira estreita e inovadora, ao exercício da cidadania, ao desempenho ativo no mundo do trabalho e ao acesso à diversidade das culturas.

7 - Oferecer maiores opções para os estudantes no interior dos sistemas, mediante programas flexíveis que facilitem um trânsito por suas estruturas, permitirá atender de modo eficiente seus interesses e vocações específicas, provendo-lhes acesso a novas graduações de natureza polivalente e acorde com a evolução das demandas no mundo do trabalho. Tudo isso exige aperfeiçoar a articulação entre os distintos níveis de formação, mecanismos educativos formais e não formais, assim como programas compatíveis com o trabalho. Superar a segmentação e a desarticulação entre carreiras e instituições, avançando em direção a sistemas de Educação Superior fundados na diversidade, permitirá a democratização, o pluralismo, a originalidade e a inovação acadêmica e institucional, firmemente sustentada na autonomia universitária. Igualmente, imprescindíveis são a desconcentração e a regionalização da oferta educativa, tanto para buscar a eqüidade territorial como para facilitar a incorporação dos atores locais na Educação Superior.

8 - As tecnologias de informação e comunicação devem contar com pessoal idôneo, experiências validadas e um sistema de estrito controle da qualidade para ser uma ferramenta positiva de expansão geográfica e temporal do processo de ensino-aprendizagem.

9 - Dada a virtualização dos meios educativos, seu uso intensivo nos processos de ensino-aprendizagem e a tendência ao crescimento acelerado, o papel da Educação Superior se reveste de suma importância na formação de pessoas com senso crítico e formas de pensamento capazes de transformar a informação em conhecimento, para o bom exercício de suas profissões e liderança nos setores públicos e privados.

10 - A Educação Superior terá que efetivar o desenvolvimento de políticas de articulação com todo o sistema educativo, colaborando na formação de sólidas bases cognitivas e de aprendizagem nos níveis precedentes, de tal maneira que os estudantes que ingressam ao nível superior possam contar com os valores, as habilidades, destrezas e capacidades para poder adquirir, construir e transferir conhecimentos em benefício da sociedade. A Educação Superior tem uma clara responsabilidade na formação de professores para todo o sistema educativo, assim como na consolidação da pesquisa pedagógica e produção de conteúdos educativos. Os Estados devem assumir, em sua plenitude, a prioridade de garantir uma Educação de qualidade para todos, a partir da Educação inicial até 
a superior. Nesse sentido, as políticas de acesso à Educação Superior devem também considerar a necessidade da implementar de programas de ensino e pesquisa de qualidade nos programas de pós-graduação.

11 - É fundamental reconhecer o corpo docente como ator fundamental do sistema educativo, garantindo sua formação, capacitação permanente, adequadas condições laborais e regimes de trabalho, salário e carreira profissional que permitam tornar efetiva a qualidade no ensino e na pesquisa.

12 - É indispensável garantir a universalização da Educação média. Igualmente, a incorporação de toda a população às dinâmicas do conhecimento exige, por parte das instituições de Educação Superior, o desenvolvimento de alternativas e trajetórias educativas direcionadas a certificações para o trabalho, a alfabetização digital e o reconhecimento de experiências e saberes adquiridos fora dos sistemas formais. Neste sentido, deve resgatar-se, entre outras, a experiência das Universidades Populares dos inícios do reformismo universitário.

13 - As instituições de Educação Superior da Região necessitam e merecem melhores formas de governo, capazes de responder às transformações demandadas pelos contextos internos e externos. Isso exige a profissionalização dos dirigentes e uma vinculação clara entre a missão e propósitos da instituição e os instrumentos de gestão.

\section{D - Valores sociais e humanos da Educação Superior}

1 - É preciso concretizar grandes mudanças nas formas de acessar, construir, produzir, transmitir, distribuir e utilizar o conhecimento. Conforme postulado pela UNESCO em outras oportunidades, as instituições de Educação Superior, e, em particular, as Universidades, têm a responsabilidade de realizar a revolução do pensamento, pois esta é fundamental para acompanhar o resto das transformações.

2 - Reivindicamos o caráter humanista da Educação Superior, em função do qual ela deve estar orientada à formação integral de pessoas, cidadãos e profissionais, capazes de abordar com responsabilidade ética, social e ambiental os múltiplos desafios implicados no desenvolvimento endógeno e a integração de nossos países, e participar ativa, crítica e construtivamente na sociedade.

3 - É necessário promover o respeito e a defesa dos direitos humanos, incluindo: o combate a toda forma de discriminação, opressão e dominação; a luta pela igualdade, a justiça social, a eqüidade de gênero; a defesa e o enriquecimento de nossos patrimônios culturais e ambientais; a segurança e soberania alimentar e a erradicação da fome e a pobreza; o diálogo intercultural com pleno respeito pelas identidades; a promoção de uma cultura de paz, tanto quanto a unidade latino-americana e caribenha e a cooperação com os povos do Mundo. Estes formam parte dos compromissos vitais da Educação Superior 
e têm de expressar-se em todos os programas de formação, assim como nas prioridades de pesquisa, extensão e cooperação interinstitucional.

4 - A Educação Superior, em todos os seus âmbitos de ação, deve reafirmar e fortalecer o caráter pluricultural, multiétnico e multilíngüe de nossos países e de nossa região.

5 - As instituições de Educação Superior devem avançar na configuração de uma relação mais ativa com seus contextos. A qualidade está vinculada à pertinência e à responsabilidade com o desenvolvimento sustentável da sociedade. Isso exige impulsionar um modelo acadêmico caracterizado pela indagação dos problemas em seus contextos; a produção e transferência do valor social dos conhecimentos; o trabalho conjunto com as comunidades; uma pesquisa científica, tecnológica, humanística e artística fundada na definição explícita dos problemas detectados, de solução fundamental para o desenvolvimento do país ou da região e o bem-estar da população; uma tarefa ativa de divulgação, vinculada à criação de uma consciência cidadã, sustentada no respeito aos direitos humanos, e à diversidade cultural; um trabalho de extensão que enriqueça a formação, colabore na identificação de problemas para a agenda de pesquisa e crie espaços de ação conjunta com distintos atores sociais, especialmente os mais excluídos e marginalizados.

6 - É necessário promover mecanismos que permitam, sem prejuízo da autonomia, a participação de distintos atores sociais na definição de prioridades e políticas educativas, assim como na avaliação das mesmas.

\section{E - A Educação científica, humanística e artística e o desenvolvimento integral e sustentável}

1 - A Educação Superior tem um papel imprescindível na superação das discrepâncias científicas e tecnológicas atuais em relação a países mais desenvolvidos e no interior da Região. Tais distorções ameaçam a perpetuação das situações de subordinação e pobreza em nossos países. É necessário incrementar o investimento público em ciência, tecnologia e inovação, assim como assegurar a formulação de políticas públicas para estimular investimentos crescentes por parte das empresas. Estes investimentos devem estar dirigidos ao fortalecimento das capacidades nacionais e regionais para a geração, transformação e aproveitamento do conhecimento, incluindo a formação qualificada, o acesso à informação, os equipamentos necessários, a constituição de equipes e comunidades científicas integradas em rede.

2 - As políticas nacionais, regionais e institucionais devem estar direcionadas fundamentalmente para a transformação dos modelos de relação entre os grupos de pesquisa acadêmica e os usuários do conhecimento, sejam estes empresas de produção, serviços públicos ou comunidades, de forma que as 
necessidades sociais e produtivas estejam articuladas com as capacidades acadêmicas e sejam definidas linhas de pesquisa prioritárias.

3 - O desenvolvimento das capacidades científicas, tecnológicas, humanísticas e artísticas com qualidade evidente e rigorosa deve estar vinculado a uma perspectiva de sustentabilidade. O esgotamento do modelo predominante de desenvolvimento se evidencia na contraposição entre as necessidades humanas, os modos de consumo e a conservação da habitabilidade do Planeta. Trata-se de propiciar enfoques que conjuguem a atenção aos problemas sociais, econômicos e ambientais, reduzindo a fome, a pobreza e a iniqüidade, com a manutenção da biodiversidade e os sistemas de suporte da vida na Terra. A Educação é crucial para transformar valores que hoje estimulam um consumo não sustentável. As instituições de conhecimento têm um papel fundamental na orientação das novas tecnologias e da inovação em direção a sistemas de consumo-produção que não condicionem as melhoras no bem-estar ao consumo crescente de energia e materiais.

4 - As novas tecnologias convergentes formam parte da dinâmica contemporânea do desenvolvimento científico-técnico que transformará as sociedades no curso das próximas décadas. Nossos países deverão superar novos e difíceis desafios para poder gerar e utilizar este conhecimento, introduzi-lo e adaptá-lo a metas sociais e econômicas. É necessário prestar especial atenção às barreiras e potencializar a construção de bases e plataformas científico-tecnológicas endógenas.

5 - O processo de construção de uma agenda em ciência, tecnologia e inovação compartilhada pela universidade latino-americana e caribenha deve gerar o conhecimento que nosso desenvolvimento e o bem-estar de nossos povos demandam. Deve também propiciar uma atividade científica fundada nas necessidades sociais e uma crescente compreensão da ciência como um assunto público que diz respeito à sociedade em seu conjunto.

6 - Deve incrementar-se a difusão e a divulgação do conhecimento científico e cultural na sociedade, concedendo aos cidadãos a oportunidade de participar nas decisões sobre assuntos científicos e tecnológicos que possam afetá-los, direta ou indiretamente, buscando convertê-los em suporte consciente das mesmas e, ao mesmo tempo, abrindo o sistema científico à crítica social.

7 - Tão importantes como a geração e socialização do conhecimento nas áreas de ciências exatas, naturais e tecnologias de produção são os estudos humanísticos, sociais e artísticos com a finalidade de fortalecer perspectivas próprias para a abordagem de nossos problemas, responder aos desafios em matéria de direitos humanos, econômicos, sociais e culturais, eqüidade, distribuição da riqueza, integração intercultural, participação, construção democrática e equilíbrio internacional, assim como de enriquecer nosso patrimônio cultural. É indispensável vencer as distâncias entre os campos científicos, técnicos, 
humanísticos, sociais e artísticos, entendendo a complexidade e a multidimensionalidade dos problemas e favorecendo a transversalidade dos enfoques, $\mathrm{o}$ trabalho interdisciplinar e a integralidade da formação.

8 - A formação em pós-graduação resulta indispensável para o desenvolvimento da pesquisa científica, tecnológica, humanística e artística, baseada em critérios rigorosos de qualidade. A pós-graduação deve estar fundamentada em linhas ativas de pesquisa e criação intelectual para garantir que sejam estudos que promovam as mais altas qualificações profissionais e a formação permanente, contribuindo efetivamente com a geração, transformação e socialização do conhecimento.

\section{F - Redes acadêmicas}

1 - A história e os avanços construídos no âmbito da cooperação têm transformado nossas instituições de Educação Superior em atores com vocação de integração regional. Mediante a constituição de redes, as instituições de Educação Superior da região podem unir e compartilhar o potencial científico e cultural que possuem para analisar e solucionar problemas estratégicos. Tais problemas não reconhecem fronteiras e sua solução depende da realização de esforços conjuntos das instituições de Educação Superior e dos Estados.

2 - As redes acadêmicas, em escala nacional e regional, são interlocutores estratégicos perante os governos. São, também, os protagonistas indicados para articular de maneira significativa identidades locais e regionais, colaborando ativamente na superação das fortes assimetrias que prevalecem na Região e no Mundo, face ao fenômeno global da internacionalização da Educação Superior.

\section{G - A emigração qualificada}

1 - Um tema que merece maior atenção é a prevenção da subtração de pessoas de alta qualificação por via da emigração. A existência de políticas explícitas por parte de países industrializados para a captação dessas pessoas provenientes dos países do Sul significa,em muitos casos para esses Estados, a perda de capacidades profissionais indispensáveis. Essa situação exige políticas públicas inadiáveis, que atendam ao problema em sua complexidade, salvaguardando o patrimônio intelectual, científico, cultural, artístico e profissional de nossos países.

2 - A emigração se vê acelerada pelo recrutamento de jovens profissionais da Região por parte dos países desenvolvidos, para suprir a redução de sua população estudantil universitária. Isso poderá ser enfrentado mediante a abertura de oportunidades locais de trabalho de acordo com suas capacidades e com o aproveitamento, mediante mecanismos que minimizem o impacto das perdas, das vantagens estratégicas que pode significar a emigração qualificada 
em outras regiões para o país de origem quando este não puder absorvê-la diretamente.

\section{H - Integração regional e internacionalização}

1 - A construção de um Espaço de Encontro Latino-Americano e Caribenho de Educação Superior (ENLACES) é fundamental e, por isso, deve formar parte da agenda dos governos e dos organismos multilaterais de caráter regional. Trata-se de uma iniciativa básica para alcançar a integração regional em seus aspectos fundamentais, a saber: o aprofundamento de sua dimensão cultural; o desenvolvimento das potencialidades acadêmicas que consolidem as perspectivas regionais em face aos mais prementes problemas mundiais; o aproveitamento dos recursos humanos para criar sinergias em escala regional; a superação de discrepâncias na disponibilidade de conhecimentos e capacidades profissionais e técnicas; a construção do saber sob a perspectiva do bem-estar coletivo e a criação de competências para a conexão orgânica entre o conhecimento acadêmico, o mundo da produção, o trabalho e a vida social, com atitude humanista e responsabilidade intelectual.

2 - No marco da consolidação do ENLACES, é necessário enfrentar:

a. a renovação dos sistemas educativos da Região, com o objetivo de alcançar uma melhor e maior compatibilidade entre programas, instituições, modalidades e sistemas, integrando e articulando a diversidade cultural e institucional;

b. a articulação dos sistemas nacionais de informação sobre Educação Superior da região para propiciar, mediante o Mapa da Educação Superior na ALC (MESALC), o mútuo conhecimento entre os sistemas como base para a mobilidade acadêmica e como insumo para políticas públicas e institucionais adequadas.

c. o fortalecimento do processo de convergência dos sistemas de avaliação e revalidação nacionais e sub-regionais, visando dispor de padrões e procedimentos regionais de garantia de qualidade da Educação Superior e da pesquisa para projetar sua função social e pública. Os processos de revalidação regionais devem estar legitimados pela participação das comunidades acadêmicas, contar com a contribuição de todos os setores sociais e abordar a qualidade como um conceito inseparável da equidade e da pertinência;

d. o mútuo reconhecimento de estudos, títulos e diplomas, sobre a base de garantias de qualidade, assim como a formulação de sistemas de créditos acadêmicos comuns aceitos em toda a região. Os acordos sobre legibilidade, transparência e reconhecimento dos títulos e diplomas mostram-se indispensáveis, assim como a valorização de habilidades e competências dos graduados e a certificação de estudos parciais; igualmente deve ter 
continuidade o processo de conhecimento recíproco dos sistemas nacionais de pós-graduação, com ênfase na qualidade como um requisito para o reconhecimento de títulos e créditos outorgados em cada um dos países da região.

e. o fomento da mobilidade intra-regional de estudantes, pesquisadores, professores e pessoal administrativo, inclusive mediante a implementação de fundos específicos;

f. o empreendimento de projetos conjuntos de pesquisa e a criação de redes de pesquisa e docência multiuniversitárias e pluridisciplinares;

g. o estabelecimento de instrumentos de comunicação para favorecer a circulação da informação e da aprendizagem;

h. o estímulo a programas de Educação a distância compartilhados, assim como o apoio à criação de instituições de caráter regional que combinem a Educação virtual e a presencial;

i. o incremento da aprendizagem de línguas da região para favorecer uma integração regional que incorpore como riqueza a diversidade cultural e o plurilingüismo.

3 - No plano internacional é preciso fortalecer a cooperação da América Latina e do Caribe com as outras regiões do Mundo, particularmente a cooperação Sul-Sul e, dentro desta, com os países africanos.

A Conferência incumbe o IESALC de designar uma comissão encarregada de apresentar, o mais breve possível, uma pauta de ações que permita a integração progressiva das instituições de Educação Superior da Região.

Os participantes deste encontro reconhecem a tarefa substancial realizada pelo Instituto Internacional da UNESCO para a Educação Superior na América Latina e no Caribe (IESALC-UNESCO) na preparação e realização deste evento, que permitiu congregar a opinião da comunidade acadêmica regional visando à Conferência Mundial de Educação Superior, Paris 2009.

A integração acadêmica latino-americana e caribenha é uma tarefa inadiável. É necessária para criar o futuro do Continente. Os participantes da CRES 2008 ratificam o compromisso de consolidar esta tarefa. Temos a obrigação e a responsabilidade de criar um futuro próprio.

Afirmamos, com Gabriel García Márquez, em sua Colômbia ressentida, que é nossa vez de avançar em direção a "uma nova e arrasadora utopia de vida, na qual ninguém possa decidir pelos outros até a forma de morrer, na qual realmente o amor seja uma certeza e a felicidade seja possível, e na qual as estirpes condenadas a cem anos de solidão tenham por fim e para sempre uma segunda oportunidade sobre a terra”. 